\title{
Especificações de Classe -- Composição e Usos
}

Traduzido do Capitulo IX - "Position classification in the public service", por Maria Morais (do Ponto IV) - Relatório submetido à Assembléia do Serviço Público pelo Comitê de Classificação de Cargos e Planos de Vencimentos no Serviço Público.

U

MA "especificação de classe" é um retrato descrito de uma classe. Normalmente ela contém a denominação de classe, a descrição de amplitude das atribuições e responsabilidades da classe, exemplos de trabalhos ou tarefas típicas e um enunciado das qualificações necessárias ao desempenho do trabalho da classe. Esse enunciado do padrão de qualificações geralmente inclui elementos tais como educação, experiência, conhecimentos, habilidades, tirocínio, e atributos físicos e pessoais.

A redação de especificações convenientes é uma tarefa difícil e precisa, que exige rigor de análise, habilidade criadora e habilidade de fazer distinções clara e sucintamente. Também exige completo conhecimento da matéria, função ou atividade da classe e a relação que exista entre esta e as demais.

\section{OBJETIVOS DAS ESPECIFICAÇÕES DE CLASSE}

As especificações de classe se constituem no elemento de referência mais importante de um plano de classificação, pois mostram o que são as classes, que espécie de cargos nelas se enquadram e o que são as linhas de demarcação entre elas, em têrmos de fatôres de trabalho e qualificações. Nessa conformidade, há certos objetivos a atingir pelas especificações de classe na condição de veículos de informação, ao se escrever acêrca do plano de classificação. Além disso, qualquer objetivo do plano, como um instrumento de administração de pessoal, é igualmente um objetivo da especificação de classe; juntamente com as regras de administração elas constituem o principal instrumento escrito do plano.

Os principais objetivos estimados pelas especificações de classe podem ser assim sumarizados:

19) Definir os limites das respectivas classes; diferenciá-los entre si de modo que distinga cada classe de tôdas as demais, 
não apenas em têrmos de caráter geral ou espécie de trabalho, mas também em têrmos de dificuldade e responsabilidade de trabalho e qualificações.

$\left.2^{\circ}\right)$ Servir, conseqüentemente, como um guia para todos os interessados na distribuição de cada cargo nas respectivas classes.

32) Definir e padronizar as várias denominações de classe, que deverão ter tão-sòmente c significado a êles dado pelas especificações; e servir como um dicionário de denominações de classes.

4.) Servir como um conveniente registro escrito, mantido atualizado, para identificar as caracteristicas básicas de qualquer classe, para qualquer finalidade.

Assim sendo, as especificações de classe permitem o uso compreensivel do plano de classificação, de suas classes, denominações de classe, o arranjo dessas por todos os responsáveis pelo recrutamento e seleção de candidatos, pela elaboração de relatórios de eficiência funcional, promoções, transferências, exonerações, tabelas de remuneração, orçamento proposto, dotações para serviços pessoais, manutenção do plano de classificação de cargo e a realização de outras operações pessoais, fiscais, contábeis e de estatistica.

De início, uma especificação de classe deve distinguir entre uma dada classe e tôdas as demais, e portanto, deverá, de modo geral, indicar explicitamente os fatôres diferenciadores, primeiramente mencionando-os na exposição genérica das atribuições e responsabilidades; em segundo lugar, descrevendo-os na exposição das características que discriminam o trabalho; em terceiro lugar, ilustrando os objetivamente na enumeração e descrição de exemplos de trabalhos executados; e finalmente, consubstanciando-os nas relações correspondentes às habilitações.

Quando êsse objetivo houver sido alcançado, as especificações de classe servirão como um guia na distribuição de cargos nas classes, tanto na instalação do plano de classificação de cargos, como em sua futura administração. Esta é a fase mais difícil da classificação de cargos e é, ao mesmo tempo, a base na qual repousa o seu principal valor.

Também dentro dêste objetivo, está a finalidade de definir o nome pelo qual se deverão tornar conhecidos em todos os processos de administração de pessoal (não apenas classificação de cargos), tôdas as classes e todos os cargos nelas contidos, ou seja, a denominação de classe. Na administração de pessoal, como em outros setores, o valor dos nomes ou denominações está colocado em proporção direta com a uniformidade que êles são usados e compreendidos. Na elaboração de um plano de classificação as denominações são selecionadas e adotadas como o título comum para um grupo de cargos substancialmente parecidos, no 
que respeita a atribuições e responsabilidades. Mas se cada interessado interpretar à sua própria maneira o significado das denominações, estas poderão informar muito pouco ou conduzir a idéias errôneas. Para servirem à sua finalidade, como uma linguagem comum de trabalho, as denominações deverão ser usadas e compreendidas uniformemente, o que se obtém pela elaboração de especificações de classe, sendo que o conjunto dessas formará um dicionário de cargos.

Finalmente, as especificações deverão servir como fontes comuns de referência para quem tem qualquer interêsse em administração de pessoal no serviço público. São as ferramentas escritas para técnicos de pessoal, administradores, encarregados de orçamento e legisladores no planejamento e execução de qualquer fase de administração de orçamento ou de pessoal que exija conhecimento das atribuiçóes - conteúdo dos cargos e sua disposição dentro do plano de classificação. Elas propiciam entendimento comum de questões tais como a significação das denominações em têrmos de tarefa e responsabilidades ou o valor relativo das várias classes de cargos, ou as habilitações exigidas ou desejadas, questões estas que consomem tempo em demasia, se tiverem de ser analisadas e discutidas tôdas as vêzes que surgir um problema ou um "caso".

Em particular, elas servem como ampla base da qual se poderá partir para os tipos mais aperfeiçoados e detalhados de análise de cargo, às vêzes necessária na elaboração de testes, no desenvolvimento de programas de treinos específicos e melhoramento de sistemas de avaliação de eficiência funcional. Ajudam os funcionários a pensar em têrmos de atribuições - conteúdo de cargos; expõem as diferenças e similaridades na classificação de cargos individuais; e indicam as habilitações para cargos mais elevados. Em relação a um plano de remuneração, elas informam a agremiações civis e a grupos de contribuintes as espécies de serviço para os quais são atribuídas determinadas tabelas de remuneração.

Uma especificação de classe deve ser clara e compreensivel. Os resultados de análises de cargos deverão ser de tal modo mantidos e os fatôres diferenciais entre as classes de tal modo evidenciados que o leitor não tenha que se empenhar, por sua vez, em fazer novas análises para descobri-los e exumá-los de entre uma multidão de frases puramente descritivas.

\section{LIMITAÇÕES DAS ESPECIFICAÇõES DE CLASSE}

Especificações de classe, quando apropriadamente elaboradas, tornam-se instrumentos úteis na realização de tarefas relativas a pessoal. Todavia, onde se fazem necessárias análises de cargos bastante detalhadas, as especificações fornecem apenas uma base genérica como ponto de partida. 
As necessidades dos diversos setores de atividades de pessoal variam. Portanto, algumas especificações escritas com suficiente refinamento, servirão para alguns casos e para outros não.

$\mathrm{Na}$ redação de especificações de classe, tem-se verificado que, via de regra, se atribui o necessário destaque a sua futura utilização como descrições genéricas dos cargos de determinada classe. Êsse destaque, todavia, freqüentemente, transforma-se em um instrumento por demais genérico para situações onde se faz necessária uma análise mais detalhada de atribuições; ex.: para o técnico que esteja preparando testes de seleção ou elaborando currículo de treinamento em-serviço.

Considerando as limitações de tempo, verba, e pessoal, o redator deverá preparar todo o conjunto de especificações com o máximo de esmêro necessário a qualquer atividade ou problema de pessoal; ou seria esta segunda fase, êsse esmêro, parte das atribuições de seus colegas em seus respectivos setores? E' duvidoso que especificações ultra-esmeradas sejam compativeis com os objetivos administrativos da classificação de cargos. Uma das finalidades da classificação de cargos é fornecer informações marcantes sôbre cargos numa forma organizada, se bem que sucinta. Especificações que sejam adequadas e suficientemente analiticas e abrangentes para efeito de classificações, distribuições e outras atividades administrativas comuns podem não ser suficientemente detalhadas para certos tipos de problemas de elaboração de testes de seleção ou programas específicos de treinamento. Todavia, se elas são estendidas para êstes fins, ficam tão longas e "técnicas" que tornam proibitivo o seu uso por administradores em operações diárias e por outros que não sejam técnicos de pessoal.

O progresso neste setor, futuramente, decorrerá do fato de admitir-se que não haverá qualquer tipo de especificação que sirva a todos os fins da administração de pessoal com a mesma eficiência, ajustando-se melhor a uns do que a outros; que o grau. de generalização ou não da especificação de classe e sua forma. e conteúdo deverá ser determinado, em se considerando precisamente que utilização lhe será dada; e que, conseqüentemente, deverá haver vários graus de esmêro nas especificações para os diferentes fins a que se destinam. Êste ponto-de-vista já foi bem. enunciado da maneira seguinte:

As especificações de trabalho, por oferecerem uma limpida visão das tarefas e outras obrigações de cada cargo ou trabalho, tornam-se necessárias não sòmente na avaliação de trabalho para efeito de fixação de níveis salariais, como também nas entrevistas de candidatos a empregos, e ao se elaborarem testes de seleção e programas de treinamento. Para avaliação de salários, nossa principal preocupação é situar o cargo, como um todo, em relação a outros trabalhos, no sistema geral. Neste caso, a ênfase não é dada aos detalhes do trabalho, mas à síntese de tôdas as. 
atividades que o trabalho representa em relação a outras atividades funcionais, com as quais está integrado no conjunto da organização. Para efeito de testes e treinamento, todavia, preocupamo-nos principalmente com habilitações e outros detalhes do trabalho, não obstante a relação que êles tenham com outros trabalhos da organização. No primeiro caso ocupamo-nos de cargos em combinação com outros cargos, mas no segundo com êstes isoladamente.

As especificações de cargos, portanto, são elaboradas de modo diferente para êstes diferentes casos. No presente estudo, que se ocupa principalmente com problemas de avaliação para efeito de fixação de salários, interessamo-nos pela forma descritiva generalizada para obter uma idéia global do que seja o trabalho para identificação e comparação com outros trabalhos no todo do sistema. Outras formas de especificações dão realce a detalhes de certos cargos para a consideração de detalhes especiais ao se prepararem testes, examinarem candidatos, e elaborarem-se programas de treinamento. Estes não nos interessam aqui. Na forma descritiva de especificação de trabalho devemos, naturalmente, considerar os detalhes dos serviços mais do ponto- de-vista do âmbito geral ou da compreensão do trabalho do que do ponto-de-vista da avaliação de detalhes especiais de cada cargo.

As especificações de classe, preparadas como parte de um plano de classificação de cargos, deverão ser elaboradas de modo que condigam com objetivos prèviamente delineados. Naturalmente, as especificações deverão servir, ao máximo, às muitas. finalidades em que serão usadas. Ao se excederem êstes limites, contudo, ao se estenderem as especificações ou qualquer de suas partes, ou modificá-las, dando-se-lhes diferente realce para fins diferentes, encontram-se problemas futuros, que os encarregados de classificação e seus colegas de outros setores técnicos de pessoal ou administração pública deverão atacar em colaboração.

\section{TENDÊNCIAS DAS ESPECIFICAÇÕES DE CLASSE}

As especificaçốes de classe têm tomado várias formas nos: diferentes setores, mas sua estrutura usual é a seguinte:

a) Denominação da Classe: é uma denominação ou nome definitivo apôsto à classe e a todos os cargos desta; deverá ser tão descritiva quanto possivel das atribuições e responsabilidades de que se compõe a classe.

b) Enunciado das Atribuiçóes e Responsabilidades: é uma descrição global e generalizada do trabalho, i.e., das atribuições preponderantes e as responsabilidades englobadas na soma total de todos os cargos que se enquadram na classe descrita. 
c) Enunciado de Exemplos do Trabalho Executado: são ilustrações específicas das atribuições e responsabilidades exercidas nos cargos individuais típicos de uma classe.

d) Enunciado das Habilitações Minimas: é uma apresentação da educação básica, da experiência, conhecimentos, habilidade, e atributos pessoais exigidos para o exercício dos cargos da classe.

Recentemente introduziram -se certos aprimoramentos nas especificações de classe, os quais são exemplificados nos esboços que seguem:

\section{ESTADO DE ARKANSAS}

Denominação de classe

Definição da classe

Enunciado das atribuições em geral

Supervisão recebida

Supervisão exercida

Avaliação das atribuições

Exemplos das atribuições

Qualificações mínimas

Experiência e treino

Conhecimentos especializados

Habilidade, aptidões.

CIDADE DE SEATTLE

Denominação da classe

Avaliação de atribuições

Supervisão recebida

Supervisão exercida

Exemplos das atribuiçàes

Habilitação desejável

\section{ESTADO DE ALABAMA}

Denominação de classe

Descrição da classe

Enunciado Geral das atribuições

Avaliação das atribuições

Dados interpretativos

Exemplos de atribuições

Supervisão recebida

Supervisão exercida

Especificações das habilitações de ingresso, conhecimentos exigidos, perícia e habilidade, treino e experiência aceitáveis. 


\section{ESTADO DE MINNESOTA}

Denominação de classe

Enunciado geral das atribuições

Características diferenciais do trabalho

Exemplos de atribuiçóes

Habilitações desejáveis

Uma comparação da forma e conteúdo de especificações de classe, antigas e novas, indica várias tendências:

1a) Há uma tendência definida de tornar as especificações de classe mais compreensiveis àqueles não treinados em administração de pessoal. Isto determinou a adoção de uma descrição simples em estilo de relatório, em vez da convencional fórmula escrita sempre no infinitivo. Existe uma vantagem colateral no uso de enunciados expositivos escritos no tempo presente, porque êsse estilo está mais de acôrdo com a idéia de que a especificação descreve as atribuiçóes como elas são, em vez de como deveriam ser. Essa forma do infinitivo geralmente tem um caráter imperativo para aquêles não enfronhados nas técnicas de classificação e fazem-se necessários esclarecimentos para desfazer essa impressão. Por exemplo, se uma especificação declara que as atribuições da classe são "executar" ou "levar a efeito" um determinado serviço, isto pode ser interpretado como significando que o supervisor deve designar o funcionário para essa tarefa, e, em nenhuma hipótese, qualquer outra. E' possivel que êsse tipo de linguagem tenha contribuído para a idéia de que especificações detalhadas e as classes por elas descritas são em muitos casos restritivas demais para uma boa administração.

$2^{\text {a }) ~ C o m ~ a ~ m e s m a ~ f i n a l i d a d e ~ d e ~ t o r n a r ~ a ~ e s p e c i f i c a c ̧ a ̃ o ~ d e ~}$ classe mais clara, ponderou-se que o leitor não técnico não está habituado a pensar em têrmos de cargos como um todo e encontra dificuldade de aprender, ou aprenderá errôneamente, o significado dos serviços quando dispostos isoladamente, quando cada um dêles é, em realidade, parte de um cargo individual. Julga-se por isso, que as tarefas que ocorrem freqüentemente devem ser mencionadas, mesmo que não sejam típicas, no sentido de classificação, particularmente quando estas podem ser devidamente fixadas em combinação com outras tarefas, à medida que ocorram em um cargo.

3a) Existe uma forte tendência de tornar o caráter das especificações de classe mais analítico ou de maior avaliação. Esforços têm sido feitos no sentido de enunciar expressamente os fatos e fatôres que distinguem a classe que está sendo descrita de tôdas as demais. Assim sendo, os pontos nos quais se bascia a dotação de cargos à classe tornam-se claros na própria especificação em vez de serem deixados à mercê da habilidade analitica do leitor. Essa tendência é indicada pela inclusão dos deno- 
minados enunciados de "avaliação" ou de "características diferenciais" nas especificações de classe e por se agregarem fatôres de limitação ou qualificação a tarefas típicas com a finalidade de se thes atribuir caracteres diferenciais.

4a) Os enunciados de conhecimentos, habilidade, aptidões são considerados como mais fundamentais de que os de educação, experiência e treino e as duas espécies de enunciados estão sendo estabelecidas mais distintamente. Padrões de educação para qualificação, experiência e treino estão sendo considerados como tendo caráter demonstrativo, ou seja,-são considerados como prova da posse de certas espécies e determinada soma de conhecimentos e habilidade.

$5^{\text {a) }}$ Existe também a tendência de se omitirem as declarações relativas a linhas de promoção e outros dados que se incluem, mais apropriadamente, em cadastros ou regulamentos relativos a outros setores da administração.

\section{FORMA E CONTEÚDO ESSENCIAIS}

A especificação de classe consiste de cinco partes principais. Primeiro, surge a denominação de classe como um cabeçalho generalizado. Em seguida vem o enunciado generalizado, os exemplos ilustrativos de trabalho, as características diferenciais do trabalho, e um enunciado das habilitações encabeçado pelo titulo de habilitações exigidas, ou qualificações desejáveis, dependendo isto da diretriz adotada.

O enunciado generalizado é uma descrição introdutiva global do trabalho constante da classe, inclusive as atribuições e responsabilidades.

O enunciado das caracteristicas diferenciais do trabalho, de natureza interpretativa, assinala os fatôres que deram origem à criação da classe e indica em que o trabalho da classe se distingue do trabalho das outras classes, inclusive daquelas imediatamente acima ou imediatamente abaixo na mesma série. Os exemplos ilustrativos de trabalho são ilustrações selecionadas de tarefas executadas ou de responsabilidades assumidas individualmente ou em conjunto. As habilitações exigidas ou qualificações desejáveis são consideradas em têrmos de conhecimento, habilidade, aptidões ou qualidades pessoais, bem como experiência, educação ou outra prova de posse de outras qualidades exigiveis.

\section{ENUNCIADO GERAL}

A primeira parte da especificação de classe, seguinte à denominação da classe (que serve de cabeçalho geral de tôda especificação) é o enunciado geral das atribuições e responsabilidades. Trata-se de uma breve identificação, por alto, da espécie e nivel de trabalho constante da classe. Sua principal finalidade é des- 
crever a espécie de trabalho a ser executado e demonstrar em têrmos amplos o nivel de dificuldade dêsse trabalho e responsabilidade.

Em forma e conteúdo o enunciado geral é elaborado e expresso da maneira mais simples possivel, sem repetições de assuntos que tenham aparecido em outras partes da especificação. E' estabelecido, principalmente, como uma introdução ao resto do texto. Quando os enunciados gerais de tôdas as especificações de classe estiverem agrupados servirão como um breve sumário descritivo, o qual, geralmente, tem uma finalidade útil, qual seja a de prover informação onde o interêsse do leitor é casual, onde êle não está diretamente ligado à administração geral ou administração do pessoal, ou onde resumos sucintos de especificações de classe se fazem necessários para efeito de orçamento ou legislação.

O enunciado geral compõe-se comumente de umas poucas declarações escritas no indicativo presente. Expressões funcionais generalizadas, ou expressas como as que se seguem, poderão ser usadas para apresentar a declaração: executa, supervisiona; tem supervisão imediata sôbre um grupo de ...; é responsável por ..; dirige, administra, planeja, organiza; dirige, supervisiona, interpreta e faz relatórios (de pesquisas); é responsável administrativamente por ...; serve como responsável administrativo e chefe profissional de ... etc. Para muitas outras classes, têrmos mais precisos poderão ser usados, tais como: datilógrafa, inspeciona, fiscaliza, examina, monta guarda, patrulha, opera, (máquina ou aparelho de escritório); etc. Deve-se ter o cuidado de evitar expressões estereotipadas onde outras mais significativas devam ser usadas. Os itens do enunciado geral são comumente cumulativos, isto é, as atribuições descritas em cada um estão contidas em todos os cargos da classe. Âs vêzes, os itens são alternativos, cada um aplicando-se a alguns e não a todos os cargos da classe. Tal é o caso quando a classe contém cargos que fazem diferentes usos da matéria, diferentes métodos para problemas similares ou aspectos diferentes mas equivalentes de atribuições. Por exemplo:

"Serve como assistente supervisor responsável do Contador Chefe e é responsável por importante fase do trabalho; substitui o chefe na ausência dêste; ou exerce supervisão responsável sôbre um grupo de contadores ocupados em trabalho analítico de contabilidade que envolve questões importantes e difíceis.

No enunciado geral, empregam-se freqüentemente adjetivos amplos para indicar o grau ou extensão da importância, dificuldade ou responsabilidade. Isto é necessário onde a distinção entre duas classes sucessivas na mesma série não podem ser enunciadas sem um indevido alongamento dos dizeres.

Tais adjetivos não têm significação difinitiva para o leitor, até que estejam adequadamente explicados e ilustrados pelo 
conteúdo do restante da especificação de classe. Aliás, êles não têm nenhuma significação, exceto em relação a outras especificações, particularmente na mesma série de classes. Êles devem, portanto, ser compatíveis com expressões similares, de grau mais alto ou mais baixo, usadas em outras especificações de classe mais pròximamente ligadas, a fim de indicar a gradação e coordenação apropriadas. Às vêzes, torna-se conveniente decidir antecipadamente a ordem de escalonamento para tais adjetivos, como êstes poderão ser usados em diferentes especificações. Por exem plo, o que se segue poderá ser estabelecido como uma série ascendente de adjetivos para indicar dificuldade de trabalho; a rotina mais simples; de menor dificuldade do que a média; de dificuldade média; de maior dificuldade do que a média; muito difícil, excepcionalmente difícil. Expressões similares podem ser usadas na descrição de importância ou atribuições. Também aqui expressões estereotipadas deverão ser evitadas, se houver outras mais significativas.

Para efeito de distribuições de cargos nas classes, êsses adjetivos são em si sós as expressões menos úteis na especificação de classes. O seu principal valor reside no fato de mostrarem, logo ao início da especificação, que um dos fatôres que diferenciam uma classe de outra mais alta ou mais baixa é o grau ou extensão da importância, dificuldade ou responsabilidade do trabalho, e isto conduz, o leitor ou o intérprete das especificações, à consideração dêsses fatôres de distribuição e à relação que a informação dada tem com cada um dêles.

$O$ enunciado geral termina no item que diz "e executar tarefas semelhantes que lhe forem determinadas", ou outro de redação equivalente. Isto tem uma finalidade dupla. Põe em relêvo o fato de que apenas as atribuições preponderantes e caracteristicas foram descritas e que não há a preocupação em abranger, em detalhe, tôdas as tarefas contidas no cargo. Dá também realce ao fato de que o funcionário pode estar sujeito à execução de tarefas diversas das expressamente mencionadas.

\section{ASPECTOS MARCANTES DO TRABALHO}

O enunciado dos aspectos marcantes do trabalho é uma parte importante da especificação. Escrito em "linguagem direta de relatório", êle tem por função destacar aquelas características do trabalho da classe que a distinguem das demais. Deve ser suficientemente especifico para estabelecer os limites da classe. Distinções quanto a espécies de trabalho são reveladas pelos detalhes, no que tange à sua natureza essencial. Distinções quanto a níveis, ou seja, diferenciações entre a classe que está sendo descrita $\mathrm{e}$ as que se encontram imediatamente acima ou imediatamente abaixo, na mesma série, são demonstradas pela informação acêrca da dificuldade e complexidade do trabalho, a quantidade e quali- 
dade da supervisão, de não supervisão e administrativas. Como um todo, êsse enunciado abrange os fatôres essenciais de diferenciação da análise de classificação, à medida que êstes estão compreendidos nos trabalho do cargo que se situa na classe.

Via de regra, nenhuma medida é tomada visando subdividir o enunciado dos aspectos marcantes do trabalho em pequenos tópicos, tais como dificuldade e complexidade, supervisão recebida, supervisão exercida e assim por diante, a menos que a classe seja tão uniforme, ou tão pequena no seu conteúdo de cargos, que torne isto um arranjo lógico. Na maioria dos casoz o enunciado é escrito como uma unidade, de forma que as combinações de fatôres de distribuição, e os próprios fatôres, possam ser mais bem apresentados.

A dificuldade e a complexidade podem ser indicadas em têrmos de espécie e extensão da supervisão recebida, andamento do trabalho antes e depois de êste alcançar o funcionário, tipos de incumbências, métodos usados, procedimentos empregados, decisões tomadas, ação executada, contrôle de trabalho do funcionário por assessôres ou revisores e a sua variedade e amplitude. As atribuições podem ser de supervisão ou de não supervisão. Atribuições de não supervisão, por exemplo, podem ser demonstradas como sendo a responsabilidade de revisar ou inspecionar 'o trabalho de outrem; como sendo independência de ação ou decisão; recomendações ou decisões determinando, aplicando ou dizendo respeito a planos, diretrizes, operações, ou regulamentos; o atendimento do público ou outras repartições; a segurança ou a vida de outrem; ou qualquer outra responsabilidade pode também ser indicada por um item que descreva as conseqüências normais de êrro. Em geral, torna-se conveniente descrever dificuldade e responsabilidade juntas. Por exemplo:

"O trabalho de um Inspetor Eletricista acarreta, perante o público, a responsabilidade da prevenção de fôgo e de outros riscos inerentes a equipamento elétrico nas construções. Exige completa familiaridade com máquina elétrica, com teorias de eletricidade, com tôdas as leis, normas e regulamentos aplicáveis e excepcional habilidade de lidar eficientemente com o público".

"O trabalho de um Quimico-Auxiliar Sênior envolve técnicas científicas e de manipulação de considerável grau de dificuldade, se bem que os métodos a serem usados sejam profissionais. Os resultados são cuidadosamente examinados em várias fases da operação. Esste profissional não tem autoridade para agir por sua própria iniciativa, desviando-se das instruções".

"O trabalho de um Calculista Sênior requer o conhecimento de métodos de computações de alta matemática, de longa data estabelecidos e aceitos. Não requer análise de problemas, mas apenas a substituição das quantidades numéricas por simbolos em determinadas fórmulas e perfeita execução das operações 
contidas nas referidas fórmulas, e.g. cálculo integral, diferencial e operações ordinárias de trigonometria, álgebra, logaritmos, e de aritmética".

Uma característica de trabalho que se relaciona tanto com dificuldade como com responsabilidade é a maneira pela qual o supervisor controla o trabalho do funcionário, conforme o respectivo setor. Em alguns casos, o padrão de supervisão recebida será suficientemente uniforme para cada cargo na classe. Em outros casos, isto variará. Em consequiência, os itens descritivos da supervisão recebida aparecerão separadamente ou em combinação com itens descritivos de outros fatôres de dificuldade e responsabilidade, dependendo dos fatos. Segundo foi indicado (no Capitulo V), para efeito de análise clara, a supervisão que vem de cima é considerada como sendo distinta da dificuldade de trabalho, mesmo que esta possa vir a ser atingida por ela. Podem-se encontrar na mesma classe cargos que exigem supervisão imediata em tarefas dificeis, ou supervisão remota em tarefas simples, ou graus de supervisão e dificuldade em combinações. A supervisão de cima, além do mais, é similarmente intercalada com a responsabilidade individual da pessoa sujeita a supervisão. Assim sendo, a menos que uma determinada classe abranja apenas uns poucos cargos, ou seja inteiramente homogênea, a qualidade e o grau de supervisão recebida poderão variar entre os cargos dentro da classe e ser coberta apenas em combinação com outros fatôres.

A supervisão já foi discutida como um fator que entra na análise e classificação de cargos. Em particular, já foram descritas por alto as espécies e graus de supervisão mais comumente encontrados, podendo-se fazer referências a essas descrições como indicativas das variações normais na supervisão recebida ou exercida. Estas deverão ser expressas, tão precisamente quanto possível, no enunciado dos fatôres diferenciais do trabalho. Seguem-se exemplos:

"A escolha do problema a ser abordado é feita pelo supervisor em conferência com o funcionário, o qual, então, determina o método que empregará independentemente e estará livre de direção ou supervisão durante o curso do trabalho, exceto no que tange à observância das normas administrativas e à necessidade de atingir resultados satisfatórios.

Recebe orientação imediata bem como instruções freqüentes, especificas e detalhadas quanto a programas de trabalho, métodos e fins; tem pouca oportunidade de tomar atitudes ou decisões independentes, não sujeitas a revisão, salvo quanto a processos mais simples.

Está comissionado a distritos de inspeção, tendo a seu cargo tarefas específicas de fiscalização determinadas pelo InspetorChefe de Edifícios. O trabalho está sujeito a planejamento geral, 
diretrizes e objetivos do Departamento de Edifícios. O trabalho é apurado quando completo, pelo Inspetor-Chefe através do estudo dos relatórios de inspeção ou por meio do exame das exceções feitas pelos construtores ou proprietários de edifícios.

Ministram-se instruções detalhadas ao Auxiliar (Jr.) acêrca de qualquer nôvo tipo de incumbência. O serviço é examinado pelo respectivo superior, após concluido, quer através de uma etapa subseqüente no processo ou mediante uma verificação material de sua exatidão.

Entra em entendimento com o Diretor de Auto-Estradas e recebe instruções quanto a normas formuladas pelo órgão, seus objetivos e planos".

Para uma classe composta de cargos de administração e supervisão, o enunciado dos fatôres diferenciais prescreve o grau, a magnitude e o alcance da responsabilidade de supervisão de que se trata, isto é, a espécie e a quantidade da supervisão que o funcionário deverá exercer sôbre seus subordinados. A êsse respeito pode-se fazer referência à discussão dos fatôres pertinentes à avaliação da responsabilidade de supervisão.

Os enunciados da supervisão exercida sôbre subordinados são bastante informativos quando indicam o "vulto" da responsabilidade de supervisionar em têrmos de número e espécie de pessoal submetido à supervisão, de variedade e complexidade das funções dirigidas e as maneiras especificas nas quais a supervisão é realmente exercida. Seguem-se exemplos:

"Dirigir, como chére supervisor da loja de instrumentos, o trabalho de um pequeno grupo de confeccionadores de instrumentos, fazer estimativas, planejar, comissionar, explanar, acompanhar e fiscalizar serviços de construção, reparo ou ajuste de instrumentos de precisão $e$ aparelhos de desenho padrão ou especial".

"Como supervisor atuante de um pequeno grupo de Assistentes de Auditores Júnior, distribui serviço ao grupo; dá instruções e orientação; decide, individualmente, os casos mais dificeis e incomuns; revê o trabalho do grupo, sendo responsável pela sua correta execução".

"Supervisiona tôdas as obras de engenharia no Departamenta de Auto-Estradas, mediante a distribuição de serviços de caráter geral, a interpretação de normas regulamentares, objetivos e planos, e o exame de resoluções atinentes a métodos de trabalho, coordenação, produção e resultado obtidos.

O trabalho envolve problemas administrativo-profissionais, do mais alto nivel no campo do planejamento, construção e manutenção de rodovias; envolve também responsabilidade pela formulação, iniciação e julgamento da eficiência das mudanças .de métodos e normas". 